\title{
Prenatal caffeine exposure induces liver developmental dysfunction in offspring rats
}

\author{
Bo He ${ }^{1,2, *}$, Yinxian Wen ${ }^{3,4, *}$, Shuwei Hu1, Guihua Wang1, Wen Hu${ }^{1}$, Jacques Magdalou', Liaobin Chen ${ }^{3,4}$ and \\ Hui Wang 1,4
}

1Department of Pharmacology, Wuhan University School of Basic Medical Sciences, Wuhan, China

2School of Pharmaceutical Sciences and Yunnan Key Laboratory of Pharmacology for Natural Products, Kunming Medical University, Kunming, China

${ }^{3}$ Department of Orthopedic Surgery, Zhongnan Hospital of Wuhan University, Wuhan, China

${ }^{4}$ Hubei Provincial Key Laboratory of Developmentally Originated Disease, Wuhan, China

5UMR 7561 CNRS-Université de Lorraine, Faculté de Médicine, Vandoeuvre-lès-Nancy, Nancy, France

Correspondence should be addressed to H Wang: wanghui19@whu.edu.cn

*(B He and $Y$ Wen contributed equally to this work)

\begin{abstract}
We previously showed that prenatal caffeine exposure (PCE) induces intrauterine growth retardation (IUGR) and high susceptibility to nonalcoholic fatty liver disease in offspring rats, and the underlying mechanisms are associated with fetal overexposure to maternal glucocorticoids. Herein, we aimed to verify whether PCE disrupts liver development before and after birth and explore its possible programming mechanism. In vivo, reduced fetal weights and increased IUGR rates were accompanied by fetal liver developmental dysfunction in PCE rats. Increased fetal serum corticosterone and decreased insulin-like growth factor 1 (IGF1) levels were observed. Both male and female fetal livers exhibited increased glucocorticoid function-related gene (Gr/Clebp $\alpha$ ) expression and inhibited IGF1 signaling pathway (Igf1/lgf1r/Akt2) expression. At PW6, the levels of serum corticosterone and glucocorticoid function-related genes in PCE offspring livers were decreased, while serum IGF1 and liver IGF1 signaling pathway expression were increased, accompanied by obvious catch-up growth and enhanced liver function. Furthermore, in PCE adult offspring under chronic stress, serum corticosterone and liver Gr/C/ebp $\alpha$ expression levels were elevated, while the serum IGF1 and liver IGF1 signaling pathway levels were decreased. In vitro, cortisol (not caffeine) upregulated GR and C/EBP $\alpha$ expression and downregulated IGF1R expression. The IGF1R expression downregulated by cortisol was partially reversed by GR or C/EBP $\alpha$ knockdown. In conclusion, PCE-induced liver developmental dysfunction in fetal rats and catch-up growth in IUGR offspring. The mechanisms may be closely associated with GR/C/EBP $\alpha$ upregulation and IGF1/IGF1R signaling pathway downregulation in the fetal liver, caused by intrauterine programming of the liver glucocorticoid-IGF1 axis induced by glucocorticoid overexposure.
\end{abstract}

\section{Key Words}

- prenatal caffeine exposure

- glucocorticoid

- developmental toxicity

- intrauterine programming mechanism 


\section{Introduction}

Caffeine is a xanthine alkaloid that is widely present in coffee, tea, soft drink beverages, food and some analgesic drugs, making it one of the most frequently ingested psychoactive substances worldwide (Brent et al. 2011). Studies have reported that approximately $80 \%$ of all women consume caffeinated beverages for long periods, and caffeine consumption during pregnancy is quite common (Kuczkowski 2003). For example, the average daily caffeine consumption was reported as approximately $110 \mathrm{mg} /$ day in women of reproductive age in the United States. Both clinical investigations and animal experiments have demonstrated that prenatal caffeine exposure (PCE) has the potential to induce reproductive and embryonic toxicities, including intrauterine growth retardation (IUGR) (Momoi et al. 2008, Greenwood et al. 2010). Research has also shown that children who ingest food or beverages containing caffeine are strongly susceptible to obesity (James et al. 2004). Our previous studies have demonstrated that PCE can lead to fetal overexposure to maternal glucocorticoids and hypothalamic-pituitaryadrenal (HPA) axis-associated neuroendocrine metabolic programming alterations, resulting in the increased susceptibility of adult offspring to metabolic syndrome and nonalcoholic fatty liver disease (NAFLD) (Xu et al. 2012a, Wang et al. 2014). Meanwhile, we recently reported that PCE induces hyperinsulinemia, insulin resistance and high susceptibility to metabolic syndrome in 10-monthold offspring, and its underlying mechanisms might be related to neuroendocrine metabolic programming alteration disorder (Pei et al. 2017).

Studies have suggested that insulin-like growth factor 1 (IGF1) signaling plays an important role in neuroendocrine regulation (Puche \& Castilla-Cortázar 2012). IGF1 activates multiple downstream signaling pathways via phosphorylating the IGF1 receptor (IGF1R) and modulating proliferation, differentiation and metabolism in a variety of tissues and cells. Studies have also shown that IGF1 is the major mediator of prenatal and postnatal growth (Kamei et al. 2011). Previous studies have reported that glucocorticoids play vital roles in the regulation of fetal growth, development and maturation and are also important factors in metabolic syndrome in adulthood (Anagnostis et al. 2009). High levels of glucocorticoids inhibit the expression of IGF1 in various tissues and cells (Inder et al. 2010). Studies have indicated that caffeine can elevate the levels of glucocorticoids in both humans and animals (Pettenuzzo et al. 2008, Gavrieli et al. 2011). Our previous study showed that PCE induced maternal corticosterone overexposure to the fetus by downregulating placental $11 \beta$-hydroxysteroid dehydrogenase type 2 (11/-HSD2) (Xu et al. 2012b), accompanied by inhibition of the hepatic IGF1 signaling pathway (Xu et al. 2012a, Wang et al. 2014). Studies have shown that chronic stress can elevate the levels of stress hormones, such as glucocorticoids, which induce and aggravate the risk of metabolic diseases in adult (Bergmann et al. 2014). Our previous study found that PCE could increase the susceptibility of offspring to metabolic syndrome under high-fat diet and chronic stress conditions (Pei et al. 2017). Thus, intrauterine programming of the glucocorticoid-insulin-like growth factor 1 (GC-IGF1) axis induced by PCE may mediate liver developmental toxicology in offspring.

However, whether PCE-induced liver developmental dysfunction continues after birth, whether PCE possesses intrauterine programming alteration properties and the underlying molecular mechanisms are not yet known. IGF1R is a transmembrane receptor tyrosine kinase that mediates the biological functions of IGF1 (Riedemann \& Macaulay 2006). Studies have suggested that mutation of the IGF1R gene could lead to severe IGF1 resistance and contribute to IUGR (Abuzzahab et al. 2003). The effects of glucocorticoids on glucocorticoid receptors (GRs) are dependent on the circulating levels of glucocorticoids (namely, cortisol in humans and corticosterone in rodents), and glucocorticoids participate in the proliferation, differentiation and metabolism of cells via the interaction of activated GR with a variety of transcriptional factors (Kadmiel \& Cidlowski 2013, Ratman et al. 2013). CCAAT enhancer binding protein $\alpha(\mathrm{C} / \mathrm{EBP} \alpha)$ is a key member of the C/EBPs family that regulates downstream gene expression in collaboration with GR (Chapman et al. 2013). Meanwhile, C/EBP $\alpha$ also acts as an inhibitory transcriptional factor of the IGF1R gene (Zeng et al. 2010). These previous studies suggested that GR/C/EBP $\alpha /$ IGF1R signaling might mediate the intrauterine programming alterations of the GC-IGF1 axis induced by PCE.

Here, based on an established rat model of fetal overexposure to maternal glucocorticoids induced by PCE, we investigated the effects of PCE on liver development in utero and postnatal catch-up growth. We further explored its intrauterine programming mechanism by observing the metabolic phenotypes, expression of liver development-related genes and expression of liver GC-IGF1 axis-related genes before and after birth, as well as in adulthood with chronic stress. This study contributes to a better understanding of the molecular mechanisms of liver developmental dysfunction induced 
by PCE and helps to explain the intrauterine origin of adult metabolic diseases.

\section{Materials and methods}

\section{Drugs and reagents}

Caffeine (CAS No. C0750) was obtained from SigmaAldrich. Isoflurane was purchased from Baxter Healthcare (Deerfield, IL, USA). The ELISA kits for rat corticosterone (No. EC3001-1) were obtained from Assaypro (Saint Charles, MO, USA). ELISA kits for serum IGF1 concentration (No. MG100) were purchased from R \& D Systems. Antirabbit Ki-67 antibody (No. ab15580) was obtained from Abcam. Anti-rabbit GR antibody (No. 12041S), anti-rabbit glyceraldehyde-3-phosphate dehydrogenase (GAPDH) (No. 2118S) and anti-rabbit Lamin A/C (No. 2032T) were purchased from Cell Signaling Technology. Anti-goat C/EBPA antibody (No. sc-9314) was purchased from Santa Cruz Biotechnology. Reverse transcription and real-time quantitative polymerase chain reaction (RT-qPCR) kits were purchased from TaKaRa Biotechnology. Reagents used for cell culture including phosphate-buffered saline (PBS), DMSO, and Dulbecco's Modified Eagle Medium: Nutrient Mixture F-12 (DMEM/F-12) were obtained from Invitrogen. The other chemicals and reagents were of analytical grade.

\section{Animals and treatment}

Specific pathogen-free Wistar rats (with weights of 200-240g for females and 260-300g for males) were obtained from the Experimental Center of the Hubei Medical Scientific Academy (Wuhan, China) (No. 2012-2014, certification number: 42000600002258, license number: SCXK (Hubei). All animal experimental procedures were approved by the Committee on the Ethics of Animal Experiments of the Wuhan University School of Medicine (permit number: 14016) and performed in the Center for Animal Experiments of Wuhan University (Wuhan, China) according to the Guidelines for the Care and Use of Laboratory Animals of the Chinese Animal Welfare Committee.

All rats were acclimated 1 week before experimentation, and two female rats were placed together with one male rat overnight in a cage for mating. The appearance of sperm in vaginal smears confirmed mating, and the day of mating was considered gestational day (GD) 0. Details of animal feeding, mating and caffeine administration $(30,60$ and $120 \mathrm{mg} / \mathrm{kg} \times$ day) were performed as previously reported (Xu et al. 2012b). The animal experiment schedule was shown in Fig. 1. On GD 20, the pregnant rats were anesthetized with isoflurane and killed. Twelve pregnant rats were assigned to each group, and the litter size of each pregnant rat ranged from eight to fourteen at birth. IUGR was diagnosed when the body weight of an animal was two standard deviations less than the mean body weight of the control group (Eleftheriades et al. 2006). The fetal rats from each litter were decapitated to collect blood immediately, and the prepared serum samples from each litter were pooled together and immediately frozen, followed by storage at $-80^{\circ} \mathrm{C}$ for subsequent analyses. Fetal liver from each litter was separated and collected immediately. Fetal livers were randomly selected (one per litter) and fixed in 4\% paraformaldehyde for histological examinations. The remaining fetal liver of the littermates was pooled for RT-qPCR assay.

The remainder of the pregnant rats received $120 \mathrm{mg} / \mathrm{kg} \times$ day caffeine $(n=8$ for each group) were maintained until normal delivery. On postnatal day (PD) 1, the numbers of pups were normalized to eight per litter to assure adequate and standardized nutrition (ManuelApolinar et al. 2010). After weaning at postnatal week (PW) 4, three male and three female pups per litter were randomly assigned to either the control group or the PCE group. From PW10, one male and one female were subjected to chronic stress as previously reported
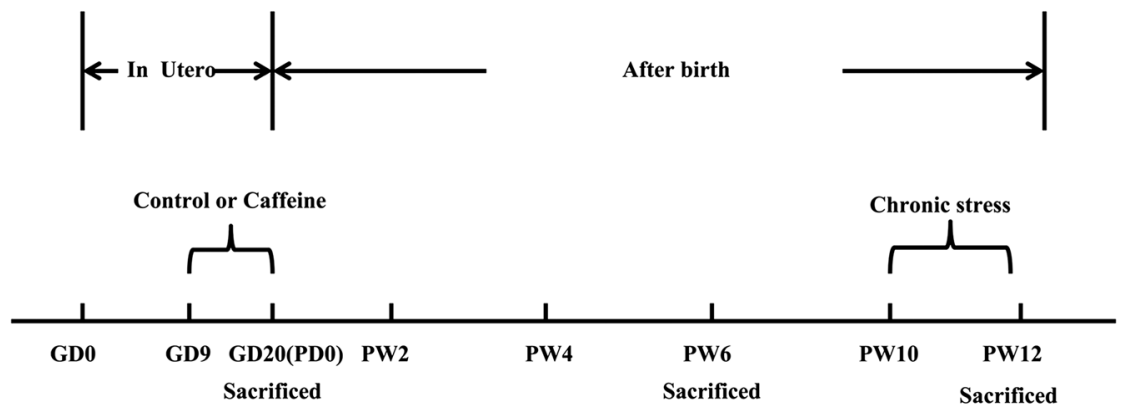

\section{Figure 1}

Schematic illustration of animal treatment. From gestational day (GD) 9-20, pregnant Wistar rats were administrated intragastrically with caffeine (30, 60 and $120 \mathrm{mg} / \mathrm{kg} \times$ day). At postnatal week (PW) 10, one rat was randomly selected from each litter for exposure to chronic stress for 2 weeks. The animals were killed at GD20, PW6 or PW12. 
(Xu et al. 2012a). The rats were made to swim five min per day in ice water $\left(5-7^{\circ} \mathrm{C}\right)$. The weights of offspring were recorded from PW1 to PW12, and the body weight gain rates were calculated. At PW6 and PW12, the offspring rats were killed under isoflurane anesthesia and decapitated to collect blood samples. The liver tissues were separated, and a section of each of five randomly selected livers from each group was fixed in a 4\% paraformaldehyde solution for histological examination. The remaining liver tissues were immediately frozen in liquid nitrogen, followed by storage at $-80^{\circ} \mathrm{C}$ for subsequent analyses.

\section{Blood sample analysis}

The concentrations of serum corticosterone and IGF1 were measured using ELISA kits following the manufacturer's protocols. The intra-assay and inter-assay coefficients of variation for corticosterone and IGF1 were 5.0 and $7.2 \%$, 5.6 and $9.1 \%$, respectively.

\section{Histological, immunohistochemistry and ultrastructural analyses}

For histological analysis, liver tissues were fixed in $4 \%$ paraformaldehyde solution overnight and stained with hematoxylin and eosin (HE) using standard procedures in graded alcohols and xylene. The sections were observed and photographed with an Olympus AH-2 light microscope (Olympus).

For immunohistochemistry assay, liver tissues were used to measure the ki67 protein expression level according to the manufacturer's instructions. Paraffinembedded tissues were cut into 5- $\mu \mathrm{m}$-thick serial sections and stained with rabbit anti-Ki67 monoclonal antibody (1:200 dilutions). Five random fields from each section were examined. The signal was visualized using light microscopy, imaged, and the number of Ki67-stained nuclei from each image was analyzed by Photo Imaging System (Nikon H550S, Japan).

For transmission electron microscopy examination, $1 \mathrm{~mm}^{3}$ tissue blocks of fetal liver samples were placed in a $2.5 \%$ glutaraldehyde solution for $10 \mathrm{~min}$. The samples were subsequently postfixed in $1 \%$ osmium tetroxide $/ 1.5 \%$ potassium ferrocyanide solution for $2 \mathrm{~h}$, washed with $0.1 \mathrm{M}$ PBS, dehydrated in gradient concentrations of ethanol and embedded in Epon 618. Epoxy blocks were sliced on an ultramicrotome (70 nm, LKB-V; LKB, Stockholm, Sweden), stained with uranyl acetate and lead citrate and examined using a Hitachi H600 transmission electron microscope (Hitachi).

\section{Cell culture and treatments}

The human embryo liver L02 cell line was obtained from the China Center for Type Culture Collection. L02 cells were plated at a density of $2 \times 10^{5}$ cells per well in six-well plates in medium (DMEM/F12 medium with $5 \%$ fetal bovine serum, $100 \mathrm{mg} / \mathrm{mL}$ streptomycin and $100 \mathrm{U} / \mathrm{mL}$ penicillin). The cells were treated with various concentrations of caffeine $(0,1,10$ and $100 \mu \mathrm{M})$ or corticosterone $(0,250,500$ and $1000 \mathrm{nM})$ for $24 \mathrm{~h}$ and then harvested to assess gene and protein' expression. To confirm the effects of GR and C/EBP $\alpha$, L02 cells were incubated with corticosterone $(1000 \mathrm{nM})$ in the absence or presence of GR and C/BEP $\alpha$ siRNA for $48 \mathrm{~h}$ and harvested for the genes' expression analysis. The mRNA expression of $G R, C / B E P \alpha$ and IGF1R in the cells was detected by RT-qPCR, using the primers listed in Supplementary Table 1 (see section on supplementary data given at the end of this article).

\section{Total RNA extraction and RT-qPCR analysis}

For RT-qPCR analysis, total RNA was isolated from liver fissures and L02 cells using TRIzol reagent (Invitrogen) according to the manufacturer's protocol. Detailed protocols for total RNA extraction and RT have been described by Tan et al. (2012). Relative standard curves were constructed for the following target genes: $G r$, $C / e b p \alpha, I g f 1, I g f 1 r$, protein kinase B (Akt2), proliferating cell nuclear antigen (Pcna), cysteine-containing aspartatespecific protease-3 (Casp-3), hepatocyte nuclear factor $4 \alpha(H n f 4 \alpha)$, albumin $(A l b)$ and alpha-fetoprotein $(A f p)$, as well as the housekeeping gene Gapdh. RT-qPCR was performed using the ABI Step OnePlus ${ }^{\mathrm{TM}}$ Real-Time PCR System (Applied Biosystems) in a $10-\mu \mathrm{L}$ reaction mixture. All subsequent 40 cycles were performed as follows: predenaturation, $95^{\circ} \mathrm{C}$ for $30 \mathrm{~s}$ and denaturation, $95^{\circ} \mathrm{C}$ for $5 \mathrm{~s}$; the annealing conditions for each gene are listed in Supplementary Table 2 .

\section{Western blot}

Western blot was performed as we have previously described (Wen et al. 2014). Briefly, the cells were washed with ice-cold $\mathrm{PBS}$ and lysed for $30 \mathrm{~min}$ at $4^{\circ} \mathrm{C}$ using RIPA buffer (25 mM HEPES pH 7.5, $50 \mathrm{mM} \mathrm{NaCl,} 1 \%$ NP40, $2.5 \mathrm{mM}$ EDTA, 10\% glycerol, 1\% Triton X-100) containing protease inhibitors $(2 \mathrm{mM} \mathrm{NaF}, 2 \mathrm{mM}$ sodium orthovanadate, $2 \mathrm{mM}$ sodium pyrophosphate, and $1 \mathrm{mM}$ protein inhibitor), and then centrifuged at $14,000 \boldsymbol{g}$ for 
10 min at $4^{\circ} \mathrm{C}$. After collection of the supernatants, the proteins were quantified by using a BCA Protein Assay Kit. Cell lysates $(40 \mu \mathrm{g})$ were loaded onto a 10\% SDS-PAGE gel for electrophoresis, and the proteins were then blotted onto a 0.45- $\mathrm{m}$ PVDF membrane (EMD Millipore), which was blocked with 5\% skimmed milk powder-TBST buffer and incubated with primary antibodies for $1 \mathrm{~h}$ at room temperature and then overnight at $4^{\circ} \mathrm{C}$. The following primary antibodies were used: anti-rabbit GR antibody (1:1000), anti-goat C/EBPA antibody (1:1000), anti-rabbit GAPDH (1:5000) and anti-rabbit Lamin A/C (1:2000). The membranes were washed three times with TBST buffer and then incubated with horseradish peroxidase (HRP)-conjugated secondary antibodies (dilution, 1:2000; Beijing Zhongshan Golden Bridge Biotechnology, Beijing, China) for $1.5 \mathrm{~h}$ at $37^{\circ} \mathrm{C}$. The signal was detected using ECL reagents. The results were quantified using Quantity One 1-Analysis software (Bio-Rad Laboratories).

\section{Chromatin-immunoprecipitation (ChIP)-PCR}

ChIP-PCR was performed as described previously (Tan et al. 2012). Briefly, L02 cells were cross-linked with $1 \%$ formaldehyde for $10 \mathrm{~min}$ at room temperature. Then, the reaction was stopped by adding glycine to a final concentration $125 \mathrm{mM}$ for $5 \mathrm{~min}$. After washing twice in ice-cold PBS, the cells were scraped and centrifuged at $3000 \boldsymbol{g}$ for $5 \mathrm{~min}$. After centrifugation, the sediments were resuspended in $500 \mu \mathrm{L}$ of MNase digestion buffer and digested by micrococcal nuclease at $37^{\circ} \mathrm{C}$ for $30 \mathrm{~min}$. The reaction was stopped by the addition of EDTA at a final concentration of $0.5 \mathrm{M}$. The samples were centrifuged at $12,000 \mathrm{~g}$ for $10 \mathrm{~min}$ and the supernatants were collected; $5 \mu \mathrm{L}$ was taken as an input sample. For reverse crosslinking, $5 \mu \mathrm{L}$ of supernatant was added to $100 \mu \mathrm{L}$ of $\mathrm{TE}$ buffer and $1 \mu \mathrm{L}$ of proteinase $\mathrm{K}$ and incubated at $55^{\circ} \mathrm{C}$ for $2 \mathrm{~h}$. The supernatant containing solubilized chromatin was incubated overnight at $4^{\circ} \mathrm{C}$ on a nutator/rocker with anti-C/EBPA antibody (preventing non-specific binding, which forms covalent bonds with Protein $G$ beads). The immunoprecipitated DNA-protein complexes were washed using low-salt wash buffer, high-salt wash buffer, LiCl wash buffer and Tris-EDTA wash buffer solutions. The complexes were eluted in $500 \mu \mathrm{L}$ of freshly prepared elution buffer ( $1 \%$ SDS, $\left.0.1 \mathrm{M} \mathrm{NaHCO}_{3}\right)$. The elution step was repeated twice. The samples were then incubated overnight at $65^{\circ} \mathrm{C}$, followed by DNA purification using a Qiagen PCR purification kit. The isolated DNA was quantified by RT-qPCR using the primers listed in Supplementary Table 3.

\section{Statistical analysis}

SPSS 18 (SPSS Science) was used for data analysis. All data presented are expressed as mean \pm s.E.M. The weights of offspring rats after birth were analyzed by repeated measures of ANOVA (Luo et al. 2014). For fetus weights, the mean weight of each litter was used for statistical analysis. The IUGR rate for each litter was determined by arcsine square root transformation before $t$-test evaluations (Engelbregt et al. 2001, Tan et al. 2012). Student's two-tailed $t$-test was used to compare the mean values of various groups as applicable. Paired $t$-tests were used to compare the means of the groups without and with chronic stress. Statistical significance was designated at $P<0.05$.

\section{Results}

Effects of PCE on the fetal body weight, IUGR rate and liver morphology of fetal rats

Fetal body weight has been used as an important indicator for IUGR diagnosis (Lee et al. 2009). As shown in Fig. 2, compared with the respective control groups, male and female fetal rats from the 60 and $120 \mathrm{mg} / \mathrm{kg} \times$ day PCE groups exhibited decreased body weights and increased IUGR rates $(P<0.01$, Fig. $2 \mathrm{~A}$ and $\mathrm{B})$. Moreover, reduced hepatic parenchymal cells were observed in the fetal livers of both $120 \mathrm{mg} / \mathrm{kg} \times$ day PCE groups (Fig. 2C). An immunohistochemical analysis showed that the numbers of Ki67-stained nuclei were reduced in the fetal liver tissues of both $120 \mathrm{mg} / \mathrm{kg} \times$ day PCE groups $(P<0.01$, Fig. 2D and E). Ultrastructural observations revealed nucleolus disappearance, chromatin margination and cell shrinkage in both $120 \mathrm{mg} / \mathrm{kg} \times$ day PCE groups (Fig. 2F). These results indicated that PCE induced IUGR and abnormal liver structures in the fetuses. The pathological changes were similar in male and female fetuses.

\section{Effects of PCE on the mRNA expression of fetal liver development- and GC-IGF1 axis-related genes}

As shown in Fig. 3, compared with the respective control groups, the higher serum corticosterone concentrations were observed in the PCE groups, particularly three of the PCE groups $(30,60$ and $120 \mathrm{mg} / \mathrm{kg} \times$ day) of male fetal rats and one of the PCE groups $(30 \mathrm{mg} / \mathrm{kg} \times$ day $)$ of female fetal rats $(P<0.05, P<0.01$, Fig. 3A). In addition, the serum IGF1 concentrations in both $120 \mathrm{mg} / \mathrm{kg} \times$ day PCE groups were lower than those in the control groups $(P<0.05$, Fig. 3B). 

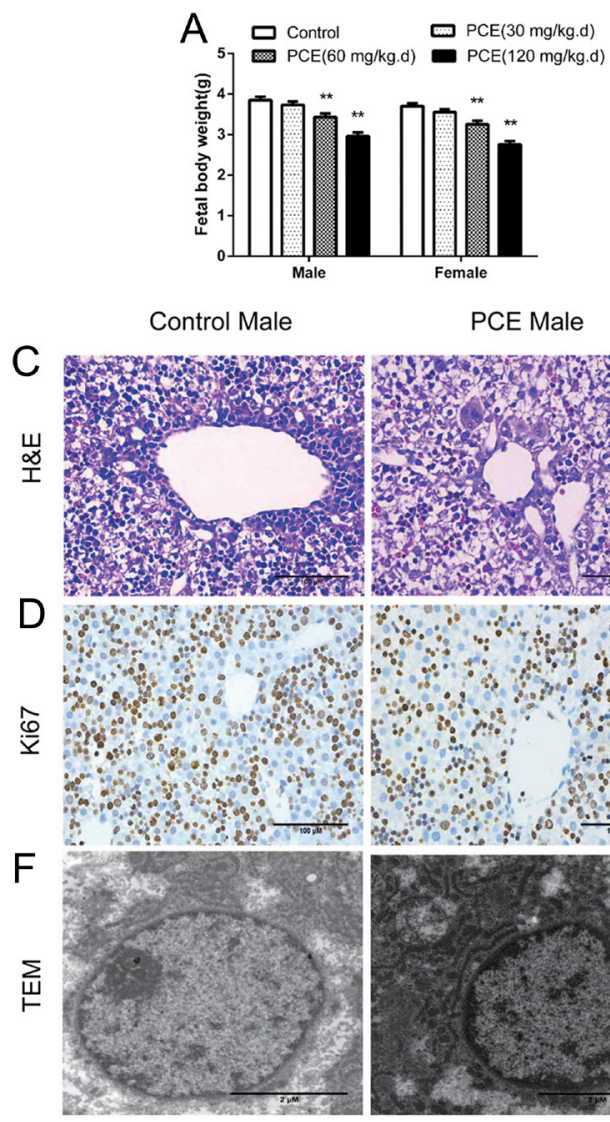

PCE Male
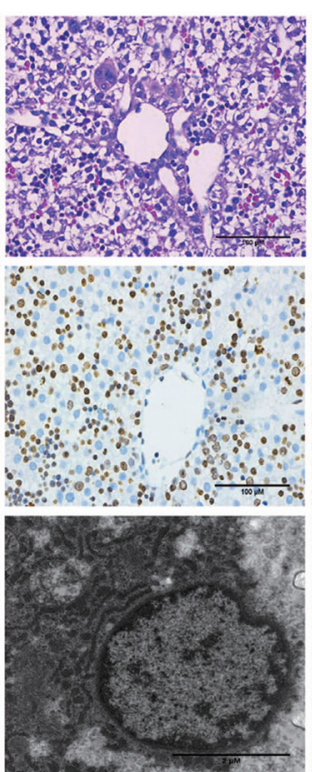

B

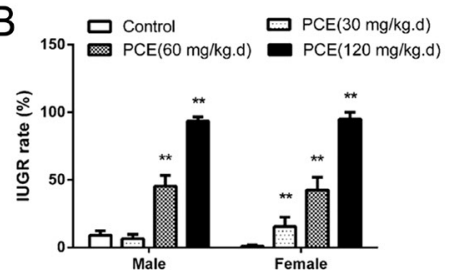

Control Female
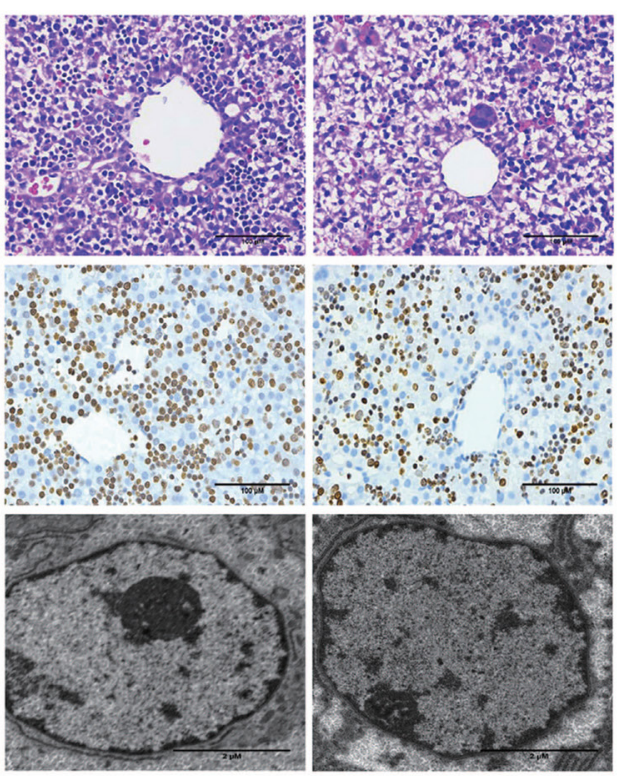

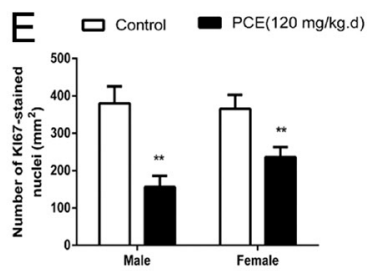

Figure 2

Effects of prenatal caffeine exposure (PCE) on the body weight, intrauterine growth retardation (IUGR) rate and the liver structure of the fetal rats on gestational day 20. (A) Fetal body weight. (B) IUGR rate (\%). (C) H\&E staining of fetal liver. (D) Immunostaining of Ki67. (E) Quantification of Ki67 expression. (F) Ultrastructure of the fetal liver (transmission electron microscopy, $\times 8,000$ ). $n=12$ pregnant rats. $n=5$ sections of each group were selected for H\&E; $n=5$ sections of each group were selected, and five random fields of each section were scored with respect to Ki67 expression. Scale bar $=100 \mu \mathrm{m}$. Mean \pm S.E.M., ${ }^{*} * P<0.01$ vs the control. A full colour version of this figure is available at https://doi.org/10.1530/JOE-19-0066.

The liver development-related genes were divided into two categories: development-promoting genes (Pcna, $H n f 4 \alpha, A l b)$ and development-suppressing genes (Casp-3, Afp) (DeBenedictis et al. 2016). Compared with the respective control groups, both PCE groups exhibited dosedependent decreased hepatic Pcna expression $(P<0.05$, $P<0.01$, Fig. 3C). The expression levels of $H n f 4 \alpha$ and $A l b$ were significantly increased in both $30 \mathrm{mg} / \mathrm{kg} \times$ day PCE groups, while the male $120 \mathrm{mg} / \mathrm{kg} \times$ day PCE group exhibited decreased $H n f 4 \alpha$ and $A l b$ expression $(P<0.05$, $P<0.01$, Fig. 3D and E). The mRNA expression of Casp-3 was noticeably increased in the male PCE groups in a dose-dependent manner $(P<0.05, P<0.01$, Fig. $3 F)$, while the female $30 \mathrm{mg} / \mathrm{kg} \times$ day PCE exhibited reduced Casp-3 expression $(P<0.05$, Fig. $3 \mathrm{~F})$. The mRNA expression of $A f p$ was increased in the male $120 \mathrm{mg} / \mathrm{kg} \times$ day PCE group and three PCE groups of females $(P<0.05, P<0.01$, Fig. $3 G)$. These results suggested that PCE inhibited the expression of genes promoting development and enhanced the expression of genes suppressing development, and no significant differences were observed between genders.

To investigate the mechanisms of PCE-induced changes in liver structure and functional fetal liver development, fetal liver GC-IGF1 axis-related gene expression was measured. Compared with the respective control groups, the mRNA expression of $\mathrm{Gr}$ in the PCE groups was increased, especially in the male fetal rat $120 \mathrm{mg} / \mathrm{kg} \times$ day PCE group and the female $30 \mathrm{mg} / \mathrm{kg} \times$ day PCE group $(P<0.05$, Fig. $3 \mathrm{H})$. The mRNA expression of $C / e b p \alpha$ in the PCE groups was significantly increased compared with that in the control groups, especially in male fetal rats from three PCE groups and female fetal rats from the $120 \mathrm{mg} / \mathrm{kg} \times$ day PCE group $(P<0.01$, Fig. 3I). The mRNA expression levels of $I g f 1$ and $I g f 1 r$ in both PCE groups were lower than those in the control groups $(P<0.05, P<0.01$, Fig. 3J and K). The mRNA expression of Akt2 was decreased in male fetuses in three PCE groups and female fetuses in the $120 \mathrm{mg} / \mathrm{kg} \times$ day PCE 

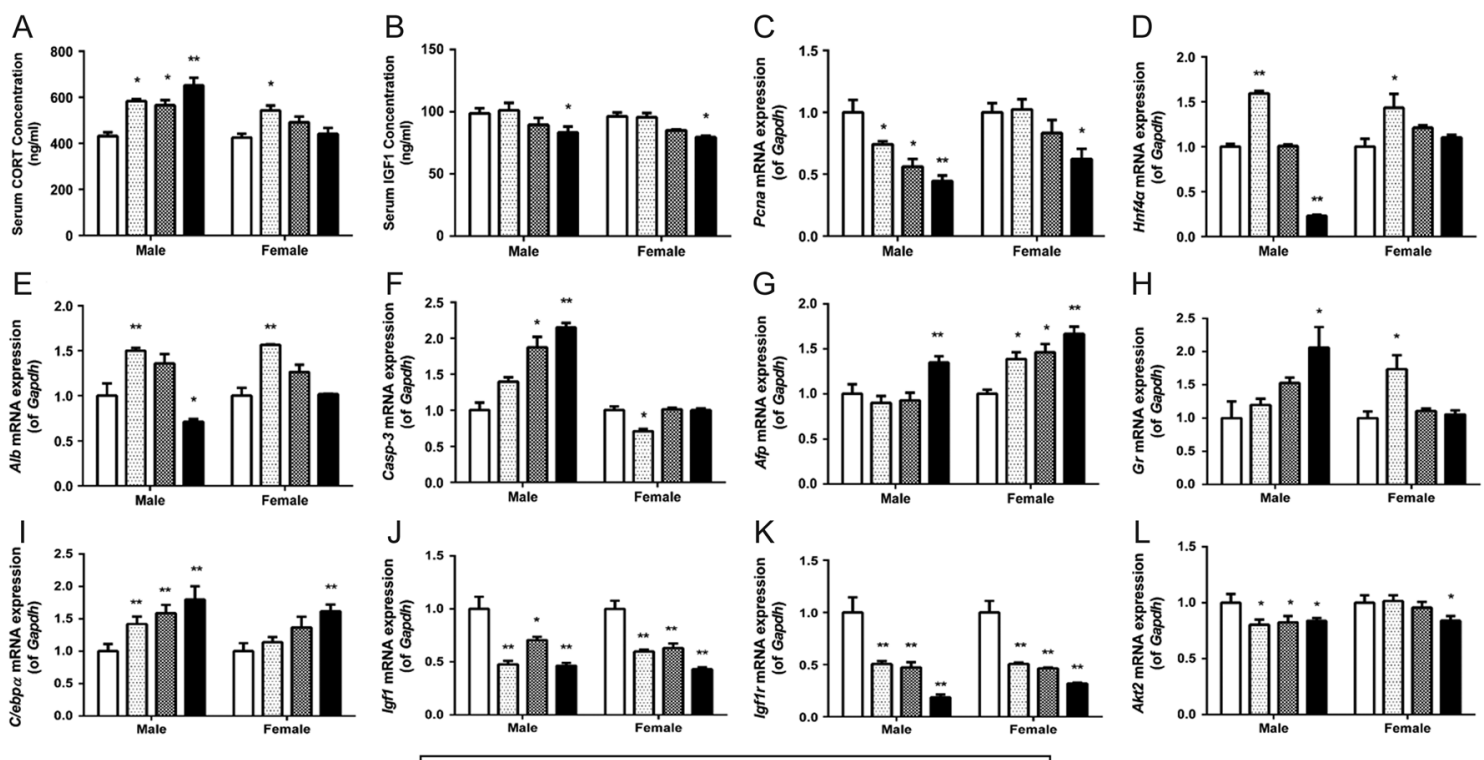

口 Control D PCE(30 mg/kg.d) $\quad$ PCE(60 mg/kg.d) PCE(120 mg/kg.d)

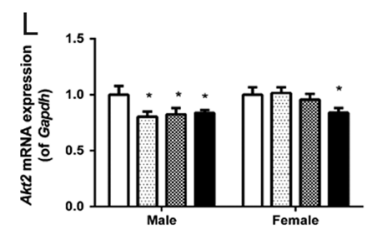

\section{Figure 3}

Effects of prenatal caffeine exposure (PCE) on serum corticosterone (CORT) content and mRNA expression levels of hepatic development- and glucocorticoid-insulin-like growth factor 1 (GC-IGF1) axis-related genes in fetal rats on gestational day 20. (A and B) ELISA of serum CORT and IGF1 concentration. (C, D and E) mRNA expression of liver development-promoting genes, including proliferating cell nuclear antigen (Pcna), hepatocyte nuclear factor $4 \alpha(H n f 4 \alpha)$ and albumin (Alb). (F and G) mRNA expression of liver development-suppressing genes, including cysteine-containing aspartatespecific protease-3 (Casp-3) and alpha-fetoprotein (Afp). ( H, I, J, K and L) mRNA expression of liver GC-IGF1 axis-related genes, including glucocorticoid receptor $(G r)$, CCAAT enhancer-binding protein $\alpha(C / e b p \alpha)$, Igf1, insulin-like growth factor 1 receptor $(I g f 1 r)$ and protein kinase B beta $(A k t 2)$. $n=12$ pooled samples from 12 different litters, Mean \pm S.E.M., $* P<0.05, * \star P<0.01$ vs. the control.

group $(P<0.05$, Fig. 3L). These results suggested that PCE increased the serum corticosterone concentration and upregulated GR and $\mathrm{C} / \mathrm{EBP} \alpha$ expression but reduced the serum IGF1 concentration and downregulated the IGF1 signaling pathway in fetal rats.

\section{Effects of PCE on the body weight, body weight gain rate and liver histology of offspring}

To further verify the effect of $120 \mathrm{mg} / \mathrm{kg} \times$ day PCE on the growth and development of offspring after birth, we investigated the alterations in liver morphology, serum corticosterone and IGF1 levels and expression of liver development- and GC-IGF1 axis-related genes. Firstly, we examined the body weight from PW1 to PW12 and calculated the body weight gain rates in offspring. As shown in Fig. 4, compared with their own control groups, the body weights of male offspring in the PCE group were lower than those in the control group from PW1 to PW6 $(P<0.01$, Fig. 4A), but the corresponding body weight gain rates showed a significant increase, especially from PW4 to PW12 $(P<0.05, P<0.01$, Fig. $4 \mathrm{~B})$. In addition, the female offspring rats in the PCE group showed significantly decreased body weights compared with those in the control group from PW1 to PW8 $(P<0.05, P<0.01$, Fig. 4C) and increased body weight gain rates from PW2 to PW12 $(P<0.05, P<0.01$, Fig. 4D). Liver histological analysis by HE staining showed that hepatocytes of both groups exhibited no obvious pathological changes relative to their control groups (Fig. 4E). Immunohistochemical analysis showed that the Ki67 protein expression levels in the livers of both PCE groups were significantly higher than those in control group rat livers $(P<0.05, P<0.01$, Fig. 4F and G). These results indicated that PCE-induced 'catch-up growth' in the IUGR offspring after birth; moreover, the liver structure tended to be normal, and proliferation-related protein expression increased at PW6.

\section{Effects of PCE on the mRNA expression of liver development- and GC-IGF1 axis-related genes in offspring}

As shown in Fig. 5, the serum corticosterone level of the male PCE group was decreased to $79.6 \%$ of the control $(P<0.01$, Fig. 5A), whereas there was decreased to $92.3 \%$ of the control in the female PCE group $(P>0.05)$. The serum IGF1 level of the male PCE group was approximately $31.8 \%$ higher than that of the control group 


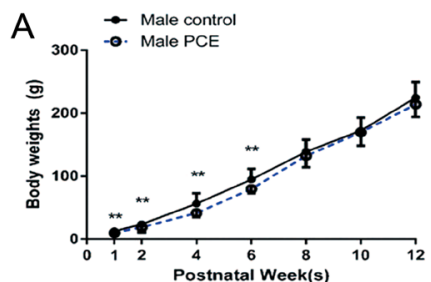

B
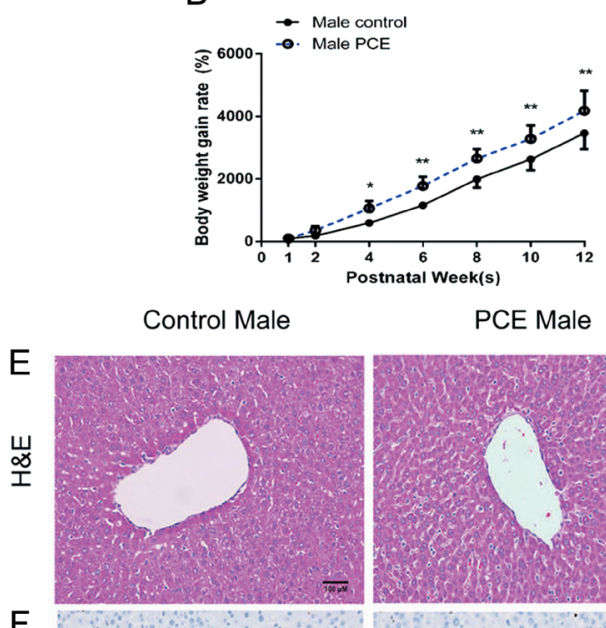

F
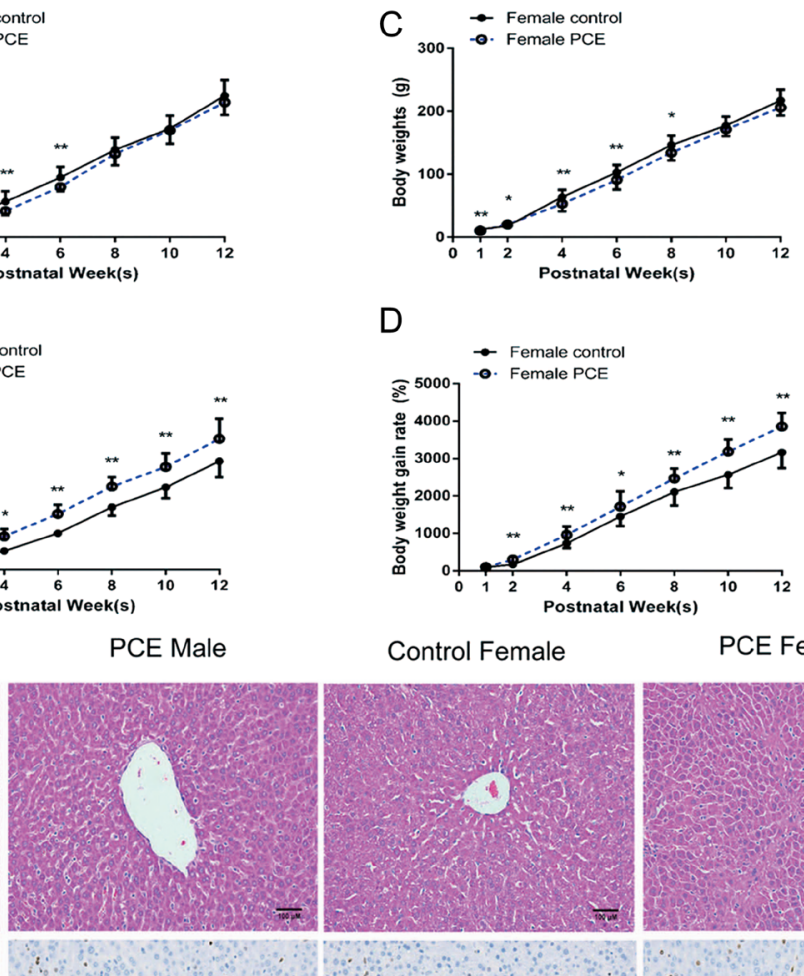

D

ִָ

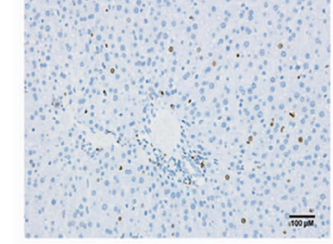

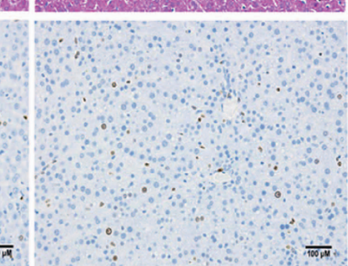

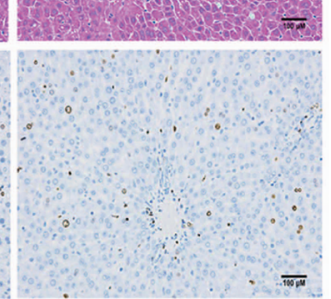

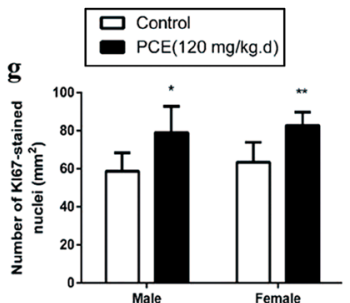

\section{Figure 4}

Effects of prenatal caffeine exposure (PCE) on the body weights, body weight gain rate and liver histology in offspring rats. (A and B) Body weights and body weight gain rates from postnatal week 1 (PW1) to 12 in male offspring. (C and D) Body weights and body weight gain rates from postnatal week 1 (PW1) to 12 in female offspring. (E) H\&E staining of liver in male and female offspring at PW6. (F) Immunostaining of Ki67 in male and female offspring at PW6. (G) Quantification of Ki67 expression in male and female offspring at PW6. $n=8$ offspring from 8 pregnant rats. $n=5$ sections of each group were selected for $\mathrm{H} \& \mathrm{E}$, and five random fields of each section scored with respect to Ki67 expression. Scale bar $=100 \mu \mathrm{m}, \mathrm{mean} \pm \mathrm{S} . \mathrm{E} . \mathrm{M} .,{ }^{*} P<0.05$, $* \star P<0.01 \mathrm{vS}$ the control. A full colour version of this figure is available at https://doi.org/10.1530/JOE-19-0066.

$(P<0.05$, Fig. 5B), and the female PCE group exhibited a $5.1 \%$ increase in the serum IGF1 level $(P>0.05)$. Additionally, to understand the mechanism underlying 'catch-up growth' mediated by PCE, we examined the expression of liver development-related genes. Compared with those in control group offspring, the mRNA expression levels of development-promoting genes (Pcna, $H n f 4 \alpha$ and $A l b)$ were significantly enhanced in both PCE groups $(P<0.05, P<0.01$, Fig. 5C, D and E). However, the expression levels of development-suppressing genes $(C a s p-3, A f p)$ only in the male PCE group were lower than those in the control groups $(P<0.01$, Fig. 5F and $G)$. These results demonstrated that PCE could enhance the liver function in PW6 offspring (increased expression of genes that promote liver development and decreased expression of genes that suppress liver development), while these changes were more obvious in male offspring.

To explore the potential mechanisms of liver function enhancement after birth in the PCE group, the mRNA expression levels of liver GC-IGF1 axis-related genes were measured. The mRNA expression of liver $G r$ in the male PCE group was lower than that in the control group $(P<0.01$, Fig. $5 \mathrm{H})$, while a decreasing trend in liver $G r$ mRNA level was observed in the female PCE group. The expression of $C / e b p \alpha$ showed a significantly decreased in the female PCE group $(P<0.05$, Fig. 5I) or decreasing trend in male PCE group $(P=0.51)$. The IGF1 signaling pathway showed a significant increase, especially the expression of $I g f 1$ and $I g f 1 r$ in the male PCE group and the expression of $I g f 1 r$ and $A k t 2$ in the female PCE group $(P<0.05, P<0.01$, 


\begin{tabular}{l|l|l|r|c|}
$\begin{array}{l}\text { Journal of } \\
\text { Endocrinology }\end{array}$ & B He, Y Wen et al. & $\begin{array}{l}\text { PCE induces liver } \\
\text { developmental dysfunction }\end{array}$ & $\mathbf{2 4 2 : 3}$ & $\mathbf{2 1 9}$ \\
\hline
\end{tabular}
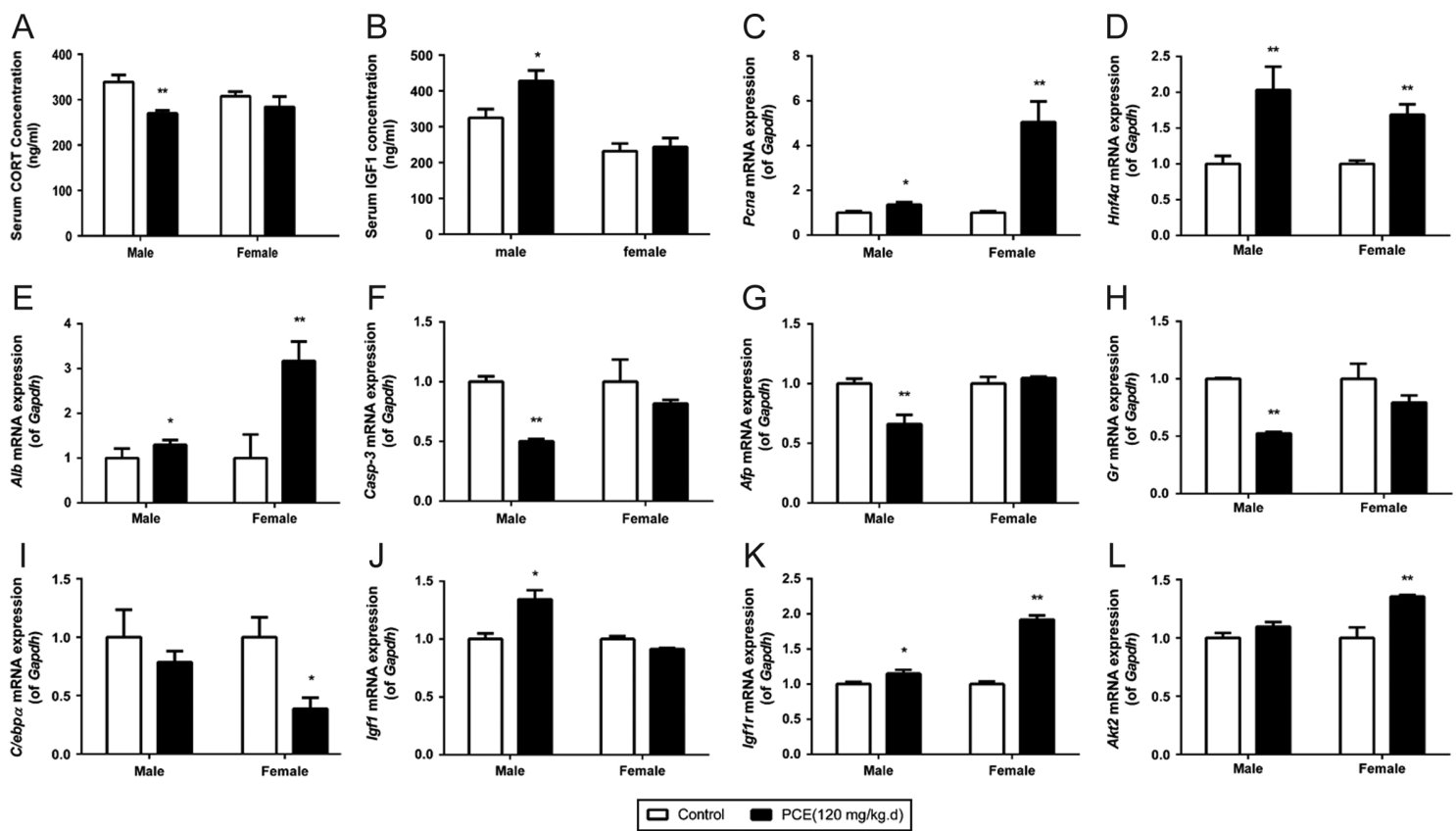

\section{Figure 5}

Effects of prenatal caffeine exposure (PCE) on serum corticosterone (CORT) content and mRNA expression levels of hepatic development-and glucocorticoid-insulin-like growth factor 1 (GC-IGF1) axis-related genes in offspring rats at postnatal week 6 (PW6). (A, B and C) mRNA expression of liver development-promoting genes, including proliferating cell nuclear antigen (Pcna), hepatocyte nuclear factor $4 \alpha(H n f 4 \alpha)$ and albumin (Alb). (D and $\mathrm{E})$ mRNA expression of liver development-suppressing genes, including cysteine-containing aspartate-specific protease-3 (Casp-3) and alpha-fetoprotein (Afp). ( $F$ and G) ELISA analysis of serum CORT and IGF1 concentration. ( $\mathrm{H}, \mathrm{I}, \mathrm{J}, \mathrm{K}$ and L) mRNA expression of liver GC-IGF1 axis-related genes, including glucocorticoid receptor (Gr), CCAAT enhancer binding protein $\alpha(C / e b p \alpha)$, Igf1, insulin-like growth factor 1 receptor (Igf1 $r$ ) and protein kinase B beta (Akt2). $n=8$ offspring from 8 pregnant rats. Mean \pm S.E.M., ${ }^{*} P<0.05,{ }^{* *} P<0.01$ vs the control.

Fig. 5J, K and L). These results suggested that PCE reduced the serum corticosterone level in offspring at PW6, inhibited the expression of liver glucocorticoid-related genes, increased the serum IGF1 level and activated the liver IGF1 signaling pathway.

\section{In vivo analysis at PW12 with/without chronic stress}

To confirm glucocorticoid-dependent programming of the IGF1 signaling pathway in the liver, we detected changes in serum corticosterone and IGF1 levels and the mRNA expression of liver GC-IGF1 axis-related genes without/with chronic stress. As shown in Fig. 6, without chronic stress, compared with those in the controls, male PCE group had increased the serum IGF1 level and liver IGF1 signaling pathway $(P<0.05, P<0.01$, Fig. 6B, E, F and G). Female PCE group showed a reduced serum corticosterone level (77.3\% of the control) and liver $\mathrm{Gr}$ expression accompanied by increased Akt2 expression $(P<0.05$, Fig. 6A, C and G). With chronic stress, the serum corticosterone level increased obviously in both PCE groups $(P<0.05, P<0.01$, Fig. $6 \mathrm{H})$. Moreover, the male PCE group had a decreased serum IGF1 level
(53.1\% of the control) $(P<0.01$, Fig. 6I), while a decreasing trend was observed in the female PCE offspring (79.4\% of the control) $(P>0.05)$. Both PCE offspring exhibited significantly increased $G r$ and $C / e b p \alpha$ expression $(P<0.01$, Fig. 6J and K). Suppressed liver IGF1 signaling was also observed in female PCE offspring, while only the expression of $I g f 1 r$ was decreased in the male PCE group $(P<0.01$, Fig. 6L, M and $\mathrm{N})$. These results suggested that PCE increased the serum corticosterone level as well as liver $G r$ and $C / e b p \alpha$ expression in rats subjected to chronic stress, accompanied by decreased serum IGF1 levels and liver IGF1 signaling pathway suppression.

\section{Effects of caffeine or corticosterone on the expression of GC-IGF1 axis-related genes in L02 cells}

To further verify the in vivo mechanisms of glucocorticoiddependent programming of the IGF1 signaling pathway induced by PCE, fetal liver L02 cells were treated with different concentrations of caffeine or corticosterone for 24 h. As shown in Fig. 7, compared with the control group, treatment with different concentrations of caffeine $(1,10$ and $100 \mu \mathrm{M})$ or cortisol $(250,500$ and $1000 \mathrm{nM})$ for $24 \mathrm{~h}$ 

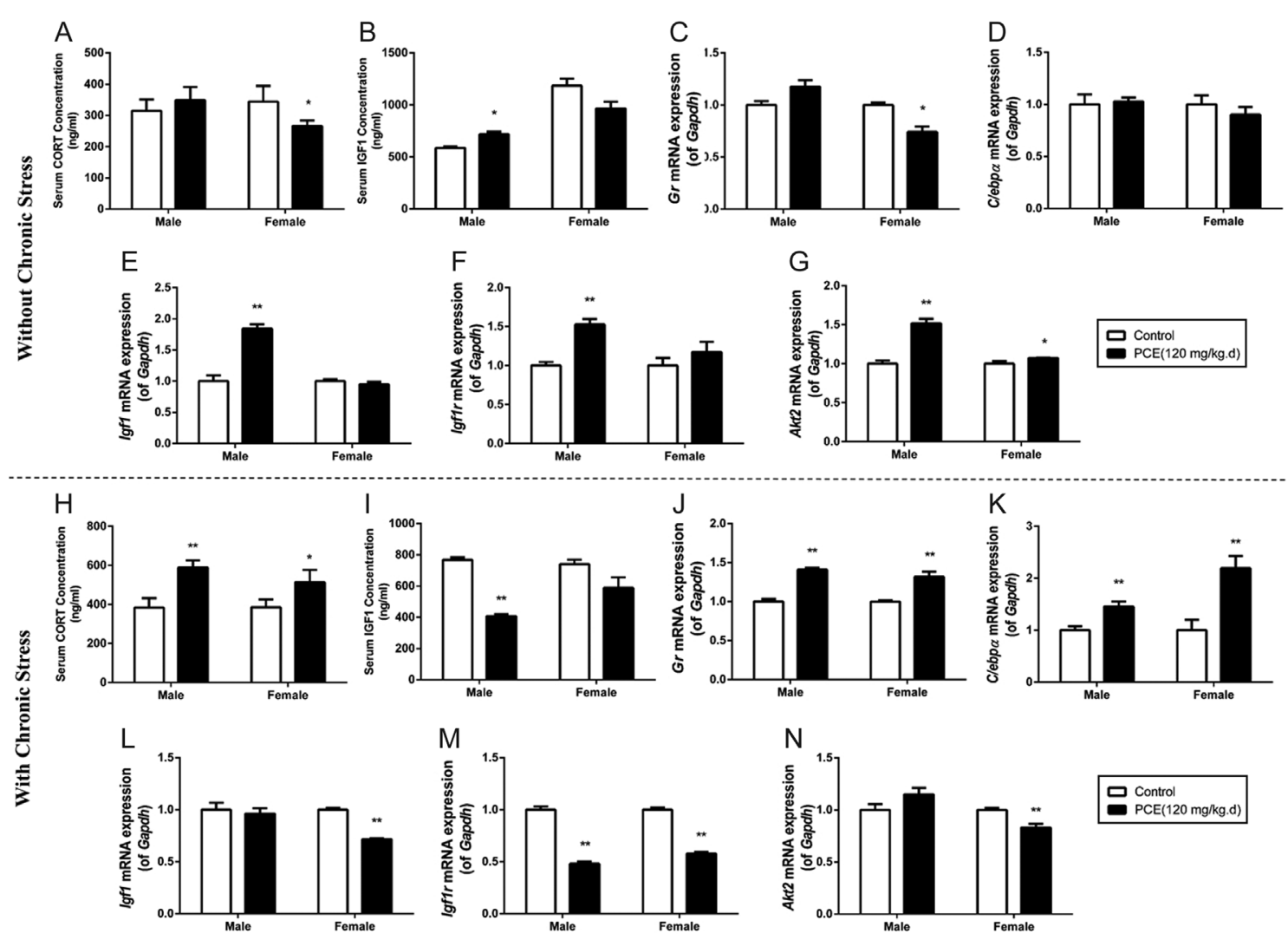

\section{Figure 6}

Effects of prenatal caffeine exposure (PCE) on serum corticosterone (CORT) content and mRNA expression levels of glucocorticoid-insulin like growth factor 1 (GC-IGF1) axis-related genes in offspring rats at postnatal week 12 (PW12) without or with chronic stress. (A and B) ELISA analysis of serum CORT and IGF1 concentrations in offspring rats at PW12 without chronic stress. (C, D, E, F and G) mRNA expression of liver GC-IGF1 axis-related genes in offspring rats at PW12 without chronic stress, including glucocorticoid receptor (Gr), CCAAT enhancer binding protein $\alpha(C /$ ebp $\alpha)$, IGF1, insulin-like growth factor 1 receptor (Igf1r) and protein kinase B beta (Akt2). (H and I) ELISA analysis of serum CORT and IGF1 concentrations in offspring rats at PW12 with chronic stress. (J, K, L, M and N) mRNA expression of liver GC-IGF1 axis-related genes, including Gr, C/ebp $\alpha$, Igf1, Igf1r and Akt2, in rat offspring at PW12 with chronic stress. $n=8$ offspring from 8 pregnant rats. Mean \pm S.E.M., $* P<0.05, * \star P<0.01$ vs the control.

induced no cytotoxicity (Fig. 7A and B). After treatment with $1-100 \mu \mathrm{M}$ caffeine for $24 \mathrm{~h}$, the mRNA expression of $I G F 1 R$ appeared to increase in a concentration-dependent manner $(P<0.05$, Fig. 7C). However, treatment with 250-1000 nM cortisol for $24 \mathrm{~h}$ decreased the IGF1R mRNA expression level in a concentration-dependent manner, and this effect was accompanied by increases in $G R$ and $C / E B P \alpha$ mRNA and protein expression $(P<0.05$, Fig. 7D, E, $\mathrm{F}$ and $\mathrm{G})$. Furthermore, the nuclear $G R$ and $C / E B P A$ protein expression levels in the $1000 \mathrm{nM}$ cortisol treatment group were higher than those in the control group $(P<0.05$, Fig. $7 \mathrm{H}$ ). These results indicated that cortisol (not caffeine) inhibited the expression of IGF1R and increased GR and C/EBPA expression.

To determine whether GR and C/EBP $\alpha$ played any role in the cortisol-induced decrease in IGF1R expression, GR siRNA and $\mathrm{C} / \mathrm{EBP} \alpha$ siRNA were applied to L02 cells for $24 \mathrm{~h}$. The mRNA expression of IGF1R was significantly reduced following treatment with $1000 \mathrm{nM}$ cortisol $(P<0.05, P<0.01$, Fig. $7 \mathrm{I}$ and $\mathrm{J})$, and the mRNA expression of $I G F 1 R$ was significantly increased following treatment with GR siRNA $(P<0.01$, Fig. 7I). After treatment with $1000 \mathrm{nM}$ cortisol+GR siRNA for $24 \mathrm{~h}$, the mRNA expression of $I G F 1 R$ was upregulated compared with that in the cortisol control group and downregulated compared with that in the GR siRNA control group $(P<0.05$, $P<0.01$, Fig. 7I). Similarly, after treatment with $1000 \mathrm{nM}$ cortisol $+\mathrm{C} / \mathrm{EBP} \alpha$ siRNA for $24 \mathrm{~h}$, the mRNA expression of $I G F 1 R$ was increased compared with that in the cortisol control group $(P<0.01$, Fig. $7 \mathrm{~J})$. As shown in Fig. $7 \mathrm{~K}$, after treatment with $1000 \mathrm{nM}$ cortisol for $24 \mathrm{~h}$, IGF1R promoter activity was increased $(P<0.01)$. After treatment with $1000 \mathrm{nM}$ cortisol and C/EBP $\alpha$ siRNA for $24 \mathrm{~h}$, IGF1R promoter activity was decreased compared with that in the cortisol control group and exhibited an increasing tendency compared with that in the $\mathrm{C} / \mathrm{EBP} \alpha$ siRNA control group $(P<0.01)$. These results suggested that GR and $\mathrm{C} / \mathrm{EBP} \alpha$ were involved in the inhibited expression of IGF1R by cortisol. 

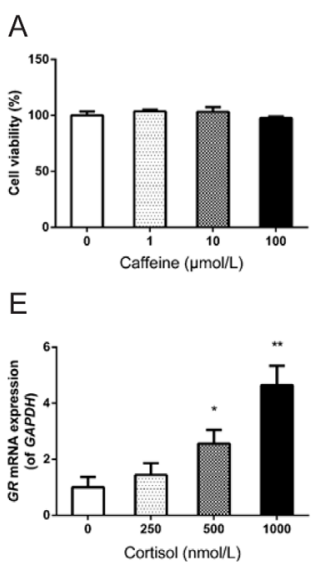

I

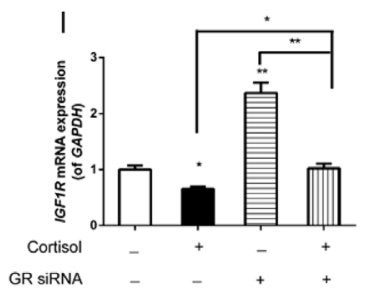

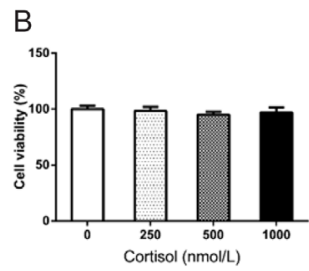

F

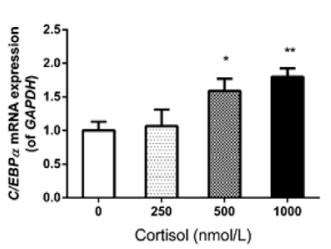

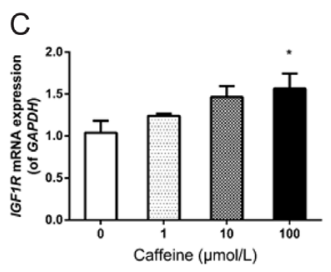

G

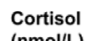
$\begin{array}{lllll}(\mathrm{nmol} / \mathrm{L}) & 0 & 250 & 500 & 1000\end{array}$

GR

C/EBPA

GAPDH

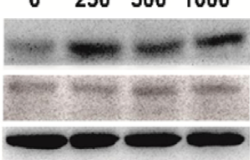

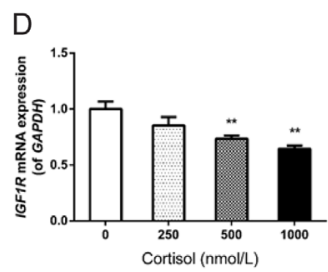

$\mathrm{H}$

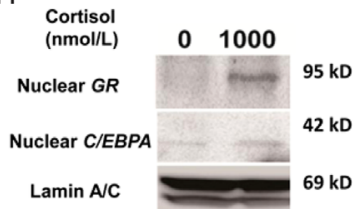

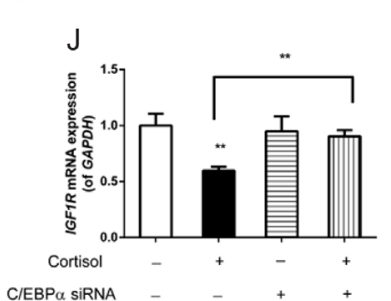

K

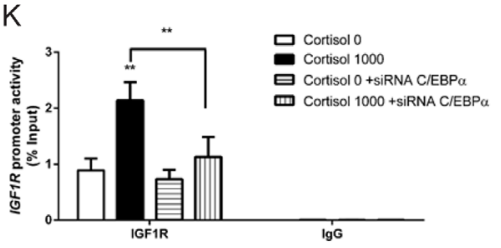

\section{Figure 7}

Effects of caffeine or cortisol treatment for $24 \mathrm{~h}$ on cell viability and the expression levels of insulin-like growth factor 1 receptor (IGF1R), glucocorticoid receptor $(G R)$ and CCAAT enhancer binding protein $\alpha(C / E B P \alpha)$ in L02 cells. (A) Cell viability after caffeine treatment. (B) Cell viability after cortisol treatment. (C) mRNA expression of IGF1R after caffeine treatment. (D, E and F) mRNA expression of IGF1R, glucocorticoid receptor (GR) and CCAAT enhancer binding protein $\alpha(C / E B P \alpha)$ after cortisol treatment. (G) Protein expression of GR and C/EBPA detected by Western blotting after cortisol treatment. (H) Protein expression of nuclear GR and C/EBPA detected by Western blotting after cortisol treatment. (I) mRNA expression of IGF1R after cortisol and GR siRNA treatment. (J) mRNA expression of IGF1R after cortisol and C/EBP $\alpha$ siRNA treatment. (K) Chromatin immunoprecipitation (ChIP)-PCR assay for the enrichment of C/EBP $\alpha$ at the IGF1R promoter after cortisol and C/EBP $\alpha$ siRNA treatment. IgG served as a negative control. All experiments were performed at least three times. Mean \pm S.E.M., $* P<0.05, * * P<0.01$ vs compared with the untreated cells.

\section{Discussion}

\section{PCE structurally and functionally inhibited the fetal liver and induced catch-up growth after birth in offspring rats with IUGR}

Developmental toxicology has been defined as the occurrence of adverseeffects on the developingorganism that may result from xenobiotic exposure in either parent prior to conception during prenatal or postnatal development, which is mainly manifested by teratogenicity, dysfunction or abnormality, growth retardation or even death. During liver development, liver-enriched transcriptional factors play a crucial role (Nagaki \& Moriwaki 2008). HNF4 $\alpha$ is a master transcriptional factor of hepatocyte differentiation and function because it regulates over $50 \%$ of the genes involved in hepatocyte-specific function (Nakhei et al. 1998). Moreover, PCNA acts as a universal marker of cell proliferation, while Casp-3 is considered a marker of cell apoptosis (Choudhary et al. 2015). In particular, ALB is a key feature of mature hepatocytes and could be used as an important marker of hepatic maturation, while AFP is commonly used as a marker of immature hepatocytes (Hyatt et al. 2008). In the present study, we found altered hepatocellular ultra-structures in PCE fetuses. These alterations primarily manifested as reduced cellularity of hepatic parenchymal cells, chromatin margination and cell shrinkage. Analysis of development-related genes in the fetal liver showed decreased expression of developmentpromoting genes (such as Pcna, $H n f 4 \alpha, A l b$ ) and enhanced expression of development-suppressing genes (such as Casp-3, Afp). These results suggested that PCE induces liver development toxicity in fetal rats.

'Catch-up growth' has been used to describe the phenomenon of fetal growth retardation caused by pathological factors, and growth acceleration occurs after removal of the growth-inhibiting condition (Reichetzeder et al. 2016). Studies have shown that IUGR induced by an unfavorable uterine environment during pregnancy induces abnormal intrauterine programming changes, has an irreversible impact on developmental trajectories, and increases susceptibility to disease after birth (Berends et al. 2013). Our previous studies have shown that PCE offspring undergo catch-up growth after birth and have 
high susceptibility to metabolic syndrome (Pei et al. 2017). In the present study, we confirmed increased body weight gain rates and Ki67 protein expression in the livers of both male and female PCE offspring. These results indicated that the IUGR offspring that experienced PCE exhibited rapid catch-up growth, accompanied by a compensatory enhancement of liver structure and functional development.

\section{Maternal glucocorticoid overexposure most likely induced liver development abnormalities before and after birth via GC-IGF1 axis programming}

During the fetal development period, IGF1 is an important factor in the differentiation and enrichment of induced stem cells including embryonic stem cells and mesenchymal stem cells. Moreover, IGF1 plays a crucial role in organogenesis and structural and functional differentiation (Magner et al. 2013). In utero, IGF1 is produced primarily in the fetal liver (Delaunay et al. 1997). After birth, liver IGF1 expression continues to rise, peaks at puberty, is maintained at a certain level, and then gradually decreases as aging occurs in a manner consistent with the development and maturity of the organism (Agrogiannis et al. 2014). Our previous studies showed that PCE increases the susceptibility of high-fat diet-induced NAFLD in offspring, which is most likely mediated by an enhanced postnatal IGF1/IGF1R pathway (Wang et al. 2014). In the present study, the hepatic IGF1/IGF1R pathway in PCE rat offspring was inhibited in utero but enhanced after birth. In addition, these changes in liver development-related genes were consistent with the hepatic IGF1/IGF1R pathway. These results suggested that PCE might alter liver development abnormalities before and after birth, resulting in changes in the IGF1/IGF1R pathway.

Glucocorticoid levels can inhibit the IGF1 level in fetal tissues, which leads to the occurrence of IUGR (Fowden et al. 2005). In our previous studies, we found that PCE increases the susceptibility to high-fat dietinduced NAFLD in offspring with IUGR, and this process appears to be mediated by intrauterine glucose and lipid metabolic programming and GC-IGF1 axis programming (Tan et al. 2012, Wang et al. 2014). In the present study, the PCE offspring in utero showed high serum corticosterone levels but liver IGF1/IGF1R signaling pathway inhibition. However, after birth, the serum corticosterone levels decreased, but the liver IGF1/IGF1R signaling pathway was enhanced at PW6. Furthermore, the high serum corticosterone levels induced by chronic stress in the PCE offspring inhibited the expression of the liver IGF1/IGF1R signaling pathway. These results indicated that the changes in the liver IGF1/IGF1R signaling pathway induced by maternal glucocorticoid overexposure in PCE offspring inhibit fetal liver development and compensatory catch-up growth after birth and increase the susceptibility to metabolic syndrome-related diseases, such as NAFLD.

In this study, we also observed some interesting phenomena on gender differences. Casp-3 mRNA expression was increased in three male PCE groups in a dose-dependent manner, while reduced only in the female $30 \mathrm{mg} / \mathrm{kg} \times$ day PCE group. The mRNA expression of $A f p$ was increased in the male $120 \mathrm{mg} / \mathrm{kg} \times$ day PCE group and three PCE groups of females. There were also differences in the expression of development-suppressing genes between male and female PCE groups in PW6 offspring. However, we also showed no significant gender differences in IGF1/IGF1R pathway changes in male and female before and after birth. As the core of the endocrine regulation system, IGF1/IGF1R signaling pathway is involved in the regulation of proliferation, differentiation, metabolism and matrix synthesis of pre- and post-natal cells (Randhawa \& Cohen 2005). The expression of development-suppressing genes, however, may be regulated not only by the IGF1/IGF1R signaling pathway, but also by other pathways. Studies have reported that high-dose acetaminophen can increase the expression of Casp-3 through JNK/p38 signaling pathway (Yiang et al. 2015). Prednisolone (synthetic glucocorticoids) induces an increased Casp-3 expression associated with the NF- $\mathrm{kB} / \mathrm{iNOS} / \mathrm{NO}$ signaling pathway (Lisakovska et al. 2017).

\section{GR/C/EBP $\alpha / I G R 1 R$ signaling might mediate intrauterine programming of the liver GC-IGF1 axis}

Glucocorticoids can regulate cell proliferation, differentiation and metabolism via interaction between GR and the transcriptional factor C/EBP $($ Ratman et al. 2013). C/EBP $\alpha$ is an important transcriptional factor that cooperates with GR to rapidly regulate downstream gene expression and plays a critical role in hepatocyte development (Chapman et al. 2013). Researchers found that $\mathrm{C} / \mathrm{EBP} \alpha-$ mutant embryos at later developmental stages exhibited increased hepatic cell apoptosis, and newborn pups in which C/EBP $\alpha$ was knocked down died primarily from hypoglycemia caused by liver dysfunction, suggesting that $\mathrm{C} / \mathrm{EBP} \alpha$ plays an important role in liver 
development (Kimura et al. 1998). Studies have also shown that $\mathrm{C} / \mathrm{EBP} \alpha$ inhibits $I G F 1 R$ gene expression via miR-122 (Zeng et al. 2010). These studies suggested that $\mathrm{C} / \mathrm{EBP} \alpha$ might participate in prenatal and postnatal liver development by negatively modulating IGF1R expression.

In the present study, fetal liver $G r$ and C/ebp $\alpha$ expression increased, but IGF1/IGF1R signaling pathway expression decreased when PCE fetuses were overexposed to maternal corticosterone. At PW6 after birth, the serum corticosterone level in the PCE offspring was inhibited, but the expression of the liver IGF1/IGF1R signaling pathway was increased. In PCE offspring at PW12 under chronic stress, the expression of $G r$ and C/ebpo was increased, while the expression of the liver IGF1/IGF1R signaling pathway was suppressed. Meanwhile, cortisol (not caffeine) inhibited hepatocyte IGF1R expression in a concentration-dependent manner in vitro. Fetal liver L02 cells treated with different concentrations of cortisol exhibited increased $G R$ and $C / E B P \alpha$ expression that was concentration dependent, and high concentrations of cortisol also induced the nuclear translocation of GR and $\mathrm{C} / \mathrm{EBP} \alpha$. Furthermore, the downregulation of $I G F 1 R$ expression by cortisol was partially reversed after GR or $\mathrm{C} / \mathrm{EBP} \alpha$ knockdown. We also found that $\mathrm{C} / \mathrm{EBP} \alpha$ bound to the IGF1R promoter region upon cortisol stimulation in L02 cells as determined using a ChIP-PCR assay. Therefore, our results suggested that high glucocorticoid levels induce intrauterine programming of the liver GC-IGF1 axis via GR/C/EBP $\alpha /$ IGR1R signaling.

\section{The advantages of PCE model and biological significances of thrifty phenotype induced by maternal glucocorticoid overexposure}

According to the World Health Organization (WHO), epidemiological evidence indicates that in pregnant women, a caffeine intake of $300 \mathrm{mg} /$ day $(5 \mathrm{mg} / \mathrm{kg} \times$ day) was associated with an increased risk for IUGR (Guilbert 2003). However, some studies have shown that some pregnant woman have a caffeine intake greater than $300 \mathrm{mg} /$ day and the intake can even reach $500 \mathrm{mg} /$ day (CARE Study Group 2008). In our previous studies, we used 20, 60 and $180 \mathrm{mg} / \mathrm{kg} \times$ day (Liu et al. 2012, Xu et al. 2012b) or 30, 60 and $120 \mathrm{mg} / \mathrm{kg} \times$ day (Wu et al. 2015) of caffeine to induce IUGR, and we observed some changes in the lowest-dose group and found a clear dose-effect relationship. Using the dose conversion between humans and rats (human: rat ratio of 1:6.17 based on body surface area comparisons) (Reagan-Shaw et al. 2008), PCE with 20 or $30 \mathrm{mg} / \mathrm{kg}$ day in rats is equivalent to 194 or $292 \mathrm{mg}$ of caffeine per day for a $60 \mathrm{~kg}$ person, which corresponds to one to two cups of coffee consumption assuming that a standard cup of brewed coffee contains approximately $150-200 \mathrm{mg}$ of caffeine.

Prenatal caffeine exposure

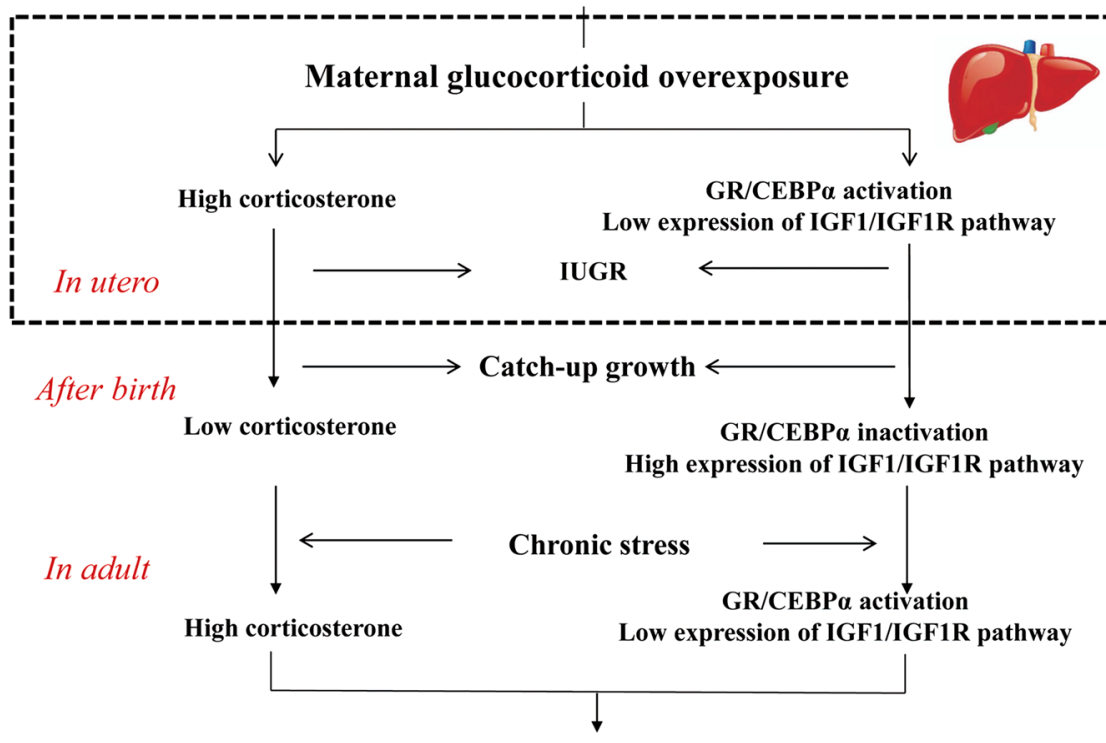

GC-IGF1/IGF1R axis intrauterine programming

Increased susceptibility to metabolic syndrome and related metabolic diseased

\section{Figure 8}

Prenatal caffeine exposure (PCE)-induced liver developmental toxicity and the related glucocorticoid-insulin-like growth factor 1 (GC-IGF1) mechanism. C/EBP $\alpha$, CCAAT enhancerbinding protein $\alpha$; GR, glucocorticoid receptor; IGF1, insulin-like growth factor 1; IGF1R, IGF1 receptor; NAFLD, non-alcoholic fatty liver disease. A full colour version of this figure is available at https://doi.org/10.1530/JOE-19-0066. 
Considering that the purpose is to explore the potential mechanism of liver developmental dysfunction before and after birth induced by PCE, we employed a caffeine dose of $120 \mathrm{mg} / \mathrm{kg} \times$ day to induce IUGR for the stability of the IUGR rat model. In addition, in our previous study, an intake of $120 \mathrm{mg} / \mathrm{kg} \times$ day caffeine resulted in caffeine concentrations of $254 \pm 11 \mu \mathrm{M}(49 \pm 2 \mu \mathrm{g} / \mathrm{mL})$ and $155 \pm 28 \mu \mathrm{M}(29 \pm 5 \mu \mathrm{g} / \mathrm{mL})$ in maternal and fetal blood, respectively (Wang et al. 2014), and these do not reach the clinical dose of intoxication $(\sim 80 \mu \mathrm{g} / \mathrm{mL})$ (Thelander et al. 2010).

Hales and Barker proposed the 'thrifty phenotype' hypothesis, which emphasized the impact of early life environmental factors on the fetus (Hales \& Barker 1992). 'Thrifty phenotype' programming is an initiative of multiple organ changes in the fetus, optimizing the use of reduced energy supplies to ensure survival (Wells 2011). In this study, we found that the fetal liver structure (decreased number of hepatocytes and Ki67 expression) and expression of fetal liver development-related genes (reduced development-promoting gene expression, increased development-suppressing gene expression) were altered induced by maternal corticosterone overexposure. These studies suggested that maternal corticosterone overexposure induced multiple gene expression changes in the fetal rat liver accompanied by a reduction in the total basal metabolic rate of the fetus and may contribute to 'thrifty phenotype' programming.

\section{Conclusion}

In summary, in the present study, we demonstrated that PCE structurally and functionally inhibited the fetal liver and induced catch-up growth after birth in rat offspring with IUGR, and the mechanisms underlying these phenomena were associated with the inhibition of $\mathrm{GR} / \mathrm{C} / \mathrm{EBP} \alpha / \mathrm{IGF} 1 \mathrm{R}$ signaling by intrauterine maternal glucocorticoid overexposure (Fig. 8). This study not only clarified the molecular mechanisms of PCE-induced liver development toxicity but also provided an experimental and theoretical basis for addressing the susceptibility to adult metabolic syndrome and related metabolic diseases in PCE-induced IUGR offspring.

\section{Supplementary data}

This is linked to the online version of the paper at https://doi.org/10.1530/ JOE-19-0066.

\section{Declaration of interest}

The authors declare that there is no conflict of interest that could be perceived as prejudicing the impartiality of the research reported.

\section{Funding}

This work was supported by grants from the National Key Research and Development Program of China (2017YFC1001300), the National Natural Science Foundation of China (No. 81430089, 81673524, 81603214, 81860665) and Hubei Province Health and Family Planning Scientific Research Project (No. WJ2017C0003).

\section{Author contribution statement}

$\mathrm{H}$ W conceived and designed the experiments. $\mathrm{B} \mathrm{H}$ and $\mathrm{Y} \mathrm{W}$ carried out the experiments and wrote the manuscript. $\mathrm{S} \mathrm{H}, \mathrm{G} \mathrm{W}$ and $\mathrm{W} \mathrm{H}$ contributed to materials, experiments and analysis of the experimental results. J $\mathrm{M}$ and $L C$ revised the manuscript. All authors reviewed the manuscript.

\section{References}

Abuzzahab MJ, Schneider A, Goddard A, Grigorescu F, Lautier C, Keller E, Kiess W, Klammt J, Kratzsch J, Osgood D, et al. 2003 IGF-I receptor mutations resulting in intrauterine and postnatal growth retardation. New England Journal of Medicine 349 2211-2222. (https://doi. org/10.1056/NEJMoa010107)

Agrogiannis GD, Sifakis S, Patsouris ES \& Konstantinidou AE 2014 Insulin-like growth factors in embryonic and fetal growth and skeletal development (Review). Molecular Medicine Reports 10 579-584. (https://doi.org/10.3892/mmr.2014.2258)

Anagnostis P, Athyros VG, Tziomalos K, Karagiannis A \& Mikhailidis DP 2009 Clinical review: the pathogenetic role of cortisol in the metabolic syndrome: a hypothesis. Journal of Clinical Endocrinology and Metabolism 94 2692-2701. (https://doi.org/10.1210/jc.20090370)

Berends LM, Fernandez-Twinn DS, Martin-Gronert MS, Cripps RL \& Ozanne SE 2013 Catch-up growth following intra-uterine growthrestriction programmes an insulin-resistant phenotype in adipose tissue. International Journal of Obesity 37 1051-1057. (https://doi. org/10.1038/ijo.2012.196)

Bergmann N, Gyntelberg F \& Faber J 2014 The appraisal of chronic stress and the development of the metabolic syndrome: a systematic review of prospective cohort studies. Endocrine Connections 3 R55-R80. (https://doi.org/10.1530/EC-14-0031)

Brent RL, Christian MS \& Diener RM 2011 Evaluation of the reproductive and developmental risks of caffeine. Birth Defects Research: Part B, Developmental and Reproductive Toxicology 92 152-187. (https://doi. org/10.1002/bdrb.20288)

CARE Study Group 2008 Maternal caffeine intake during pregnancy and risk of fetal growth restriction: a large prospective observational study. BMJ 337 a2332. (https://doi.org/10.1136/bmj.a2332)

Chapman K, Holmes M \& Seckl J 2013 11beta-Hydroxysteroid dehydrogenases: intracellular gate-keepers of tissue glucocorticoid action. Physiological Reviews 93 1139-1206. (https://doi.org/10.1152/ physrev.00020.2012)

Choudhary GS, Al-Harbi S \& Almasan A 2015 Caspase-3 activation is a critical determinant of genotoxic stress-induced apoptosis. Methods in Molecular Biology 1219 1-9. (https://doi.org/10.1007/978-1-49391661-0_1)

DeBenedictis B, Guan H \& Yang K 2016 Prenatal exposure to bisphenol A disrupts mouse fetal liver maturation in a sex-specific manner. https://joe.bioscientifica.com

https://doi.org/10.1530/JOE-19-0066 (c) 2019 Society for Endocrinology Published by Bioscientifica Ltd. Printed in Great Britain 
Journal of Cellular Biochemistry 117 344-350. (https://doi.org/10.1002/ jcb.25276)

Delaunay F, Khan A, Cintra A, Davani B, Ling ZC, Andersson A, Ostenson CG, Gustafsson J, Efendic S \& Okret S 1997 Pancreatic beta cells are important targets for the diabetogenic effects of glucocorticoids. Journal of Clinical Investigation 100 2094-2098. (https://doi.org/10.1172/JCI119743)

Eleftheriades M, Creatsas G \& Nicolaides K 2006 Fetal growth restriction and postnatal development. Annals of the New York Academy of Sciences 1092 319-330. (https://doi.org/10.1196/annals.1365.047)

Engelbregt MJ, van Weissenbruch MM, Popp-Snijders C, Lips P \& Delemarre-van de Waal HA 2001 Body mass index, body composition, and leptin at onset of puberty in male and female rats after intrauterine growth retardation and after early postnatal food restriction. Pediatric Research 50 474-478. (https://doi. org/10.1203/00006450-200110000-00009)

Fowden AL, Giussani DA \& Forhead AJ 2005 Endocrine and metabolic programming during intrauterine development. Early Human Development 81 723-734. (https://doi.org/10.1016/j. earlhumdev.2005.06.007)

Gavrieli A, Yannakoulia M, Fragopoulou E, Margaritopoulos D, Chamberland JP, Kaisari P, Kavouras SA \& Mantzoros CS 2011 Caffeinated coffee does not acutely affect energy intake, appetite, or inflammation but prevents serum cortisol concentrations from falling in healthy men. Journal of Nutrition 141 703-707. (https://doi. org/10.3945/jn.110.137323)

Greenwood DC, Alwan N, Boylan S, Cade JE, Charvill J, Chipps KC, Cooke MS, Dolby VA, Hay AW, Kassam S, et al. 2010 Caffeine intake during pregnancy, late miscarriage and stillbirth. European Journal of Epidemiology 25 275-280. (https://doi.org/10.1007/s10654-010-9443-7)

Guilbert JJ 2003 The world health report 2002 - reducing risks, promoting healthy life. Education for Health 16 230. (https://doi.org/1 $0.1080 / 1357628031000116808)$

Hales CN \& Barker DJ 1992 Type 2 (non-insulin-dependent) diabetes mellitus: the thrifty phenotype hypothesis. Diabetologia 35 595-601. (https://doi.org/10.1007/BF00400248)

Hyatt MA, Budge H \& Symonds ME 2008 Early developmental influences on hepatic organogenesis. Organogenesis 4 170-175. (https://doi. org/10.4161/org.4.3.6849)

Inder WJ, Jang C, Obeyesekere VR \& Alford FP 2010 Dexamethasone administration inhibits skeletal muscle expression of the androgen receptor and IGF-1 - implications for steroid-induced myopathy. Clinical Endocrinology 73 126-132. (https://doi.org/10.1111/j.13652265.2009.03683.x)

James J, Thomas P, Cavan D \& Kerr D 2004 Preventing childhood obesity by reducing consumption of carbonated drinks: cluster randomised controlled trial. BMJ 328 1237. (https://doi.org/10.1136/ bmj.38077.458438.EE)

Kadmiel M \& Cidlowski JA 2013 Glucocorticoid receptor signaling in health and disease. Trends in Pharmacological Sciences 34 518-530. (https://doi.org/10.1016/j.tips.2013.07.003)

Kamei H, Ding Y, Kajimura S, Wells M, Chiang P \& Duan C 2011 Role of IGF signaling in catch-up growth and accelerated temporal development in zebrafish embryos in response to oxygen availability. Development 138 777-786. (https://doi.org/10.1242/dev.056853)

Kimura T, Christoffels VM, Chowdhury S, Iwase K, Matsuzaki H, Mori M, Lamers WH, Darlington GJ \& Takiguchi M 1998 Hypoglycemiaassociated hyperammonemia caused by impaired expression of ornithine cycle enzyme genes in C/EBPalpha knockout mice. Journal of Biological Chemistry 273 27505-27510. (https://doi.org/10.1074/jbc.273.42.27505)

Kuczkowski KM 2003 Social drug use in the parturient: implications for the management of obstetrical anaesthesia. Medical Journal of Malaysia 58 147-154; quiz 155.

Lee W, Balasubramaniam M, Deter RL, Hassan SS, Gotsch F, Kusanovic JP, Goncalves LF \& Romero R 2009 Fetal growth parameters and birth weight: their relationship to neonatal body composition. Ultrasound in Obstetrics and Gynecology 33 441-446. (https://doi.org/10.1002/ uog.6317)

Lisakovska O, Shymanskyy I, Mazanova A, Khomenko A \& Veliky M 2017 Vitamin D3 protects against prednisolone-induced liver injury associated with the impairment of the hepatic NF-kappaB/iNOS/ NO pathway. Biochemistry and Cell Biology 95 213-222. (https://doi. org/10.1139/bcb-2016-0070)

Liu Y, Xu D, Feng J, Kou H, Liang G, Yu H, He X, Zhang B, Chen L, Magdalou J, et al. 2012 Fetal rat metabonome alteration by prenatal caffeine ingestion probably due to the increased circulatory glucocorticoid level and altered peripheral glucose and lipid metabolic pathways. Toxicology and Applied Pharmacology 262 205-216. (https://doi.org/10.1016/j.taap.2012.05.002)

Luo H, Deng Z, Liu L, Shen L, Kou H, He Z, Ping J, Xu D, Ma L, Chen L, et al. 2014 Prenatal caffeine ingestion induces transgenerational neuroendocrine metabolic programming alteration in second generation rats. Toxicology and Applied Pharmacology 274 383-392. (https://doi.org/10.1016/j.taap.2013.11.020)

Magner NL, Jung Y, Wu J, Nolta JA, Zern MA \& Zhou P 2013 Insulin and IGFs enhance hepatocyte differentiation from human embryonic stem cells via the PI3K/AKT pathway. Stem Cells 31 2095-2103. (https://doi.org/10.1002/stem.1478)

Manuel-Apolinar L, Zarate A, Rocha L \& Hernandez M 2010 Fetal malnutrition affects hypothalamic leptin receptor expression after birth in male mice. Archives of Medical Research 41 240-245. (https:// doi.org/10.1016/j.arcmed.2010.06.002)

Momoi N, Tinney JP, Liu LJ, Elshershari H, Hoffmann PJ, Ralphe JC, Keller BB \& Tobita K 2008 Modest maternal caffeine exposure affects developing embryonic cardiovascular function and growth. American Journal of Physiology: Heart and Circulatory Physiology 294 H2248-H2256. (https://doi.org/10.1152/ajpheart.91469.2007)

Nagaki M \& Moriwaki H 2008 Transcription factor HNF and hepatocyte differentiation. Hepatology Research 38 961-969. (https://doi. org/10.1111/j.1872-034X.2008.00367.x)

Nakhei H, Lingott A, Lemm I \& Ryffel GU 1998 An alternative splice variant of the tissue specific transcription factor HNF4alpha predominates in undifferentiated murine cell types. Nucleic Acids Research 26 497-504. (https://doi.org/10.1093/nar/26.2.497)

Pei LG, Yuan C, Guo YT, Kou H, Xia LP, Zhang L, Yan YE, Xu D \& Wang H 2017 Prenatal caffeine exposure induced high susceptibility to metabolic syndrome in adult female offspring rats and its underlying mechanisms. Reproductive Toxicology 71 150-158. (https://doi. org/10.1016/j.reprotox.2017.06.045)

Pettenuzzo LF, Noschang C, von Pozzer Toigo E, Fachin A, Vendite D \& Dalmaz C 2008 Effects of chronic administration of caffeine and stress on feeding behavior of rats. Physiology and Behavior 95 295-301. (https://doi.org/10.1016/j.physbeh.2008.06.003)

Puche JE \& Castilla-Cortázar I 2012 Human conditions of insulin-like growth factor-I (IGF-I) deficiency. Journal of Translational Medicine 10 224. (https://doi.org/10.1186/1479-5876-10-224)

Randhawa R \& Cohen P 2005 The role of the insulin-like growth factor system in prenatal growth. Molecular Genetics and Metabolism $\mathbf{8 6}$ 84-90. (https://doi.org/10.1016/j.ymgme.2005.07.028)

Ratman D, Vanden Berghe W, Dejager L, Libert C, Tavernier J, Beck IM \& De Bosscher K 2013 How glucocorticoid receptors modulate the activity of other transcription factors: a scope beyond tethering. Molecular and Cellular Endocrinology 380 41-54. (https://doi. org/10.1016/j.mce.2012.12.014)

Reagan-Shaw S, Nihal M \& Ahmad N 2008 Dose translation from anima to human studies revisited. FASEB Journal 22 659-661. (https://doi. org/10.1096/fj.07-9574LSF)

Reichetzeder C, Dwi Putra SE, Li J \& Hocher B 2016 Developmental origins of disease - crisis precipitates change. Cellular Physiology and Biochemistry 39 919-938. (https://doi.org/10.1159/000447801) https://joe.bioscientifica.com

https://doi.org/10.1530/JOE-19-0066
(C) 2019 Society for Endocrinology Published by Bioscientifica Ltd. Printed in Great Britain 
Riedemann J \& Macaulay VM 2006 IGF1R signalling and its inhibition. Endocrine-Related Cancer 13 (Supplement 1) S33-S43. (https://doi. org/10.1677/erc.1.01280)

Tan Y, Liu J, Deng Y, Cao H, Xu D, Cu F, Lei Y, Magdalou J, Wu M, Chen L, et al. 2012 Caffeine-induced fetal rat over-exposure to maternal glucocorticoid and histone methylation of liver IGF-1 might cause skeletal growth retardation. Toxicology Letters 214 279-287. (https://doi.org/10.1016/j.toxlet.2012.09.007)

Thelander G, Jonsson AK, Personne M, Forsberg GS, Lundqvist KM \& Ahlner J 2010 Caffeine fatalities - do sales restrictions prevent intentional intoxications? Clinical Toxicology 48 354-358. (https://doi. org/10.3109/15563650903586752)

Wang L, Shen L, Ping J, Zhang L, Liu Z, Wu Y, Liu Y, Huang H, Chen L \& Wang H 2014 Intrauterine metabolic programming alteration increased susceptibility to non-alcoholic adult fatty liver disease in prenatal caffeine-exposed rat offspring. Toxicology Letters $\mathbf{2 2 4}$ 311-318. (https://doi.org/10.1016/j.toxlet.2013.11.006)

Wells JCK 2011 The thrifty phenotype: an adaptation in growth or metabolism? American Journal of Human Biology 23 65-75. (https:// doi.org/10.1002/ajhb.21100)

Wen Y, Li J, Tan Y, Qin J, Xie X, Wang L, Mei Q, Wang H, Magdalou J \& Chen L 2014 Angelica sinensis polysaccharides stimulated UDP-sugar synthase genes through promoting gene expression of IGF-1 and IGF1R in chondrocytes: promoting anti-osteoarthritic activity. PLoS ONE 9 e107024. (https://doi.org/10.1371/journal.pone.0107024)
Wu YM, Luo HW, Kou H, Wen YX, Shen L, Pei LG, Zhou J, Zhang YZ \& Wang H 2015 Prenatal caffeine exposure induced a lower level of fetal blood leptin mainly via placental mechanism. Toxicology and Applied Pharmacology 289 109-116. (https://doi.org/10.1016/j. taap.2015.09.007)

Xu D, Wu Y, Liu F, Liu YS, Shen L, Lei YY, Liu J, Ping J, Qin J, Zhang C, et al. $2012 a$ A hypothalamic-pituitary-adrenal axis-associated neuroendocrine metabolic programmed alteration in offspring rats of IUGR induced by prenatal caffeine ingestion. Toxicology and Applied Pharmacology 264 395-403. (https://doi.org/10.1016/j.taap.2012.08.016)

Xu D, Zhang B, Liang G, Ping J, Kou H, Li X, Xiong J, Hu D, Chen L, Magdalou J, et al. 2012b Caffeine-induced activated glucocorticoid metabolism in the hippocampus causes hypothalamic-pituitaryadrenal axis inhibition in fetal rats. PLOS ONE 7 e44497. (https://doi. org/10.1371/journal.pone.0044497)

Yiang GT, Yu YL, Lin KT, Chen JN, Chang WJ \& Wei CW 2015 Acetaminophen induces JNK/p38 signaling and activates the caspase9-3-dependent cell death pathway in human mesenchymal stem cells. International Journal of Molecular Medicine 36 485-492. (https://doi. org/10.3892/ijmm.2015.2254)

Zeng C, Wang R, Li D, Lin XJ, Wei QK, Yuan Y, Wang Q, Chen W \& Zhuang SM 2010 A novel GSK-3 beta-C/EBP alpha-miR-122insulin-like growth factor 1 receptor regulatory circuitry in human hepatocellular carcinoma. Hepatology 52 1702-1712. (https://doi. $\operatorname{org} / 10.1002 /$ hep.23875)

Received in final form 18 June 2019

Accepted 4 July 2019 (c) 2019 Society for Endocrinology Published by Bioscientifica Ltd. 